\section{The Need for}

an Integrative

Conceptual

Framework for

Addressing

Mental Health

Challenges During

the COVID-19

Pandemic

\section{BAYAN JALALIZADEH}

\section{Abstract}

The burden of mental illness ${ }^{1}$ across the globe, already significant, has grown dramatically since the onset of the COVID-19 pandemic. This is, in part, due to limitations in the current conceptual frameworks

\section{A note on terminology: Literature} on mental health and illness uses a wide and ever-changing vocabulary to describe the topic. For simplicity, this paper will use the terms "mental health condition," "mental illness," and "psychiatric illness" interchangeably. This paper also refers to "depressive disorders," which includes a set of particular diagnoses and symptoms: major depressive disorder, persistent depressive disorder, and disruptive mood dysregulation disorder, among a few others. "Anxiety disorders" refers to specific diagnoses as well: generalized anxiety disorder, social anxiety disorder, specific phobias, and OCD, among a few others. for understanding mental illness and resulting methods of practice. This paper provides an overview of the state of mental health and illness in the world, summarizes the prevailing frameworks and practices, and introduces a potential framework which could guide a response to the mental health challenges of the pandemic.

\section{Résumé}

Le fardeau des maladies mentales dans le monde, déjà important, s'est considérablement accru depuis le début de la pandémie de COVID-19. Ce phénomène est attribuable, en partie, aux limites des cadres conceptuels actuels permettant de comprendre la maladie mentale ainsi qu'aux méthodes de pratique qui en découlent. Cet article donne un aperçu de l'état de la santé et de la maladie mentale dans le monde, résume les cadres et les pratiques qui ont cours et présente un cadre qui pourrait permettre de répondre aux défis de santé mentale découlant de la pandémie.

\section{Resumen}

La carga de las enfermedades mentales en todo el mundo, que ya es significativa, ha aumentado drásticamente desde el inicio de la pandemia del COVID-19. Este aumento se debe, en parte, a limitaciones de los marcos conceptuales actuales para comprender las enfermedades mentales y los métodos de práctica resultantes. Este artículo proporciona una descripción general del estado de la salud y la enfermedad mental en el mundo, resume los marcos y prácticas predominantes e introduce un marco potencial que podría orientar una respuesta a los desafíos de salud mental de la pandemia. 
Estimates of the prevalence and impact of mental illnesses across the world were already concerning prior to the COVID-19 pandemic. Around twenty percent of the world's children and adolescents lived with a mental health condition needing treatment (GBD). Depressive disorders had a global twelve-month prevalence estimated at 3.72 percent, with 4.25 percent in high-income countries (HICs) and 3.43 percent in low- and middle-income countries (LMICs); anxiety disorders had a twelve-month prevalence of 4.03 percent, with 5.23 percent in HICs and 3.65 percent in LMICs; and substance use disorders, a twelve-month prevalence of 2.34 percent, with 3.92 percent in HICs and 1.59 percent in LMICs (GBD). These illnesses are devastating in their effects: those with severe mental health conditions die, on average, an entire ten to twenty years earlier than the general population (GBD). These illnesses can prevent afflicted individuals from participating fully in community life, or even in their own. And where the common paths of bodily illnesses often end in organ failure, many mental health conditions can lead to the most tragic of end results, suicide. Still a taboo topic among many cultures, the specter of suicide is ever-present in virtually every locality. It is currently the second-leading cause of death in young people aged fifteen to twenty-nine (GBD), and it takes the lives of nearly 800,000 people per year, which equates to one person taking their own life every forty seconds (GBD).
Without proper longitudinal studies using consistent measurement methods, we cannot know whether the emerging epidemiological data throughout the course of the COVID-19 pandemic represent a transient occurrence or a long-term pattern; nevertheless, the results thus far are even more concerning than the statistics prior to the pandemic. Recent meta-analyses found that the pooled global prevalence of depression is currently twenty-five percent-a seven-fold increase from the pre-pandemic rate - and found similarly heightened rates of anxiety (Bueno-Notivol et al.). It appears that these increases in prevalence are generalized global trends and not simply due to outlier countries. For example, prevalence of depressive symptoms and disorders in China is twenty-eight percent, and prevalence of anxiety symptoms and disorders is twenty-five percent (Ren et al. 4-6). Ethiopia, the United Kingdom, Iran, and Italy, among other countries, have likewise reported a massive increase in individuals exhibiting depressive and anxiety symptoms (Ambaw et al. 4-6; Bitew; Pierce et al. 887; Jahanshahi; Sani et al.). Even if individuals only experience a partial set of the clinical symptoms that characterize a depressive or anxiety disorder, which are sometimes referred to as subthreshold disorders, evidence shows that they still feel a substantial decrement in health status (Ayuso-Mateos et al. 367-70). Statistics like these are not completely unexpected. In fact, multiple studies have revealed that when epidemics of infectious disease strike, 
a strong correlation is seen with rising rates of mental health consequences (Shultz et al.; Yip et al. 88-90).

With such alarming statistics arriving daily, it is necessary to ask: What factors have caused such an increase in the rates of mental health conditions during the COVID-19 pandemic, and do we have an appropriate framework to address these factors?

The scientific community has been working for decades to determine the numerous, interconnected variables impacting rates of mental illness. Each condition involves its own specific risk factors and protective factors. Among such factors are genetic predisposition, age, sociodemographic factors, early and recent life experiences, and physical health status (Michael et al. 140-41; Kessler et al. 379-81; Hettema et al. 1569-73; Blanco et al. 758-59; Dobson and Dozois; Rowland and Marwaha 259-62). While an exhaustive analysis of all the contributing factors would be too lengthy a discussion for the scope of this paper, the emerging literature reveals that in the context of the COVID-19 pandemic, the following psychological factors prominently increase the risk of mental illness: chronic stress; the increasing reality of social isolation; and the loss of hope, replaced with uncertainty and fear (Gabrielli and Lund; Xiong et al. 57-60; Hwang 1217-20; Satici et al.; Serafini et al.). For instance, while small, contained amounts of stress can be a positive motivator for action in the short-term, persistently high levels of stress over time (chronic stress), or excessively high levels of stress in a short time, can actually lead to loss of brain mass in several areas and over-activation of hormone pathways, increasing the risk of developing behavioral disturbances and depressive disorders such as major depressive disorder and persistent depressive disorder (Brodal 369; McEwen 175; Sarahian et al.; Reynaud 41-42; Fenster 542). Likewise, loneliness, when prolonged, can increase the risk of developing depressive and substance use disorders and attempting suicide (Cacioppo et al., "Loneliness" 5; Cacioppo et al., "Toward" 17). During the pandemic and subsequent lockdowns, many have felt the toll of these experiences.

Once we understand some of the factors precipitating our current mental health crises, and in order to find effective solutions, it would be helpful to look at the current frameworks for understanding and treating mental illness. This paper aims to review the existing mental health framework and propose the consideration of a modified framework, guided by the Bahá'í Writings, which draws on previously developed Bahá'í-inspired frameworks to highlight the need to move toward a spiritually informed understanding of mental illnesses that can adequately address all the factors that play a role in their development. As discussed in more detail below, this modified framework would add two important dimensions to the current model. First, it considers the spiritual reality of the individual as an essential dimension, which can help to provide solutions for 
spiritual and existential problems such as the finding of meaning in suffering, among other challenges which the prevailing model does not fully address. Second, it considers the realities of the community and institutions - not just individuals - which can serve to alleviate or exacerbate mental illnesses.

\section{Current Frameworks AND LiMITATIONS}

The observation and study of mental illnesses in modern science have varied origins, from ideas about "hysteria" among women to beliefs of supernatural possession or characterological failings (Wallace IV and Gach 199220, 353-78, 590-620; Freedheim and Weiner 337-56; Tasca et al. 111-17). The field of human psychology has advanced remarkably in the past century, allowing us to conceptualize unconscious patterns of thought (ego psychology), perceptions of interpersonal dynamics (object relations theory), and the meeting of deep-rooted human needs (attachment theory) as roadmaps of human behavior, to name just a few contributions (Wallace IV and Gach 520-30, 631-55, 658-70). In parallel, research of anatomical structures and physiological processes has helped clinicians to diagnose and treat disorders in mood, addiction, psychosomatic syndromes, and many other conditions. This conception that mental illnesses are brain illnesses is known as the "medical model" of disease (Griesinger 1-4; Liang 22-24). In recent years, these psychological and biomedical approaches have been combined to conceive of a model called the "biopsychosocial formulation" of mental illness (Engel). In this framework, scholars see human thought and behavior as emergent from an interaction between genetic, anatomic, and physiologic qualities (biological); phenomena aligned with psychodynamic and cognitive-behavioral theories (psychological); and environmental situations and events which make up one's human experience (social). The biopsychosocial model operates as a framework for mental health practitioners to conceptualize the interrelated issues within a patient and address them in an individualized manner. As a result, treatment of illnesses using this framework can include changing lifestyle factors, administering appropriate medicines, providing targeted psychotherapy, modifying interpersonal relationships, and building immediate networks of support (Engel 108-21; Borrell-Carrió et al. 578-81; Schotte et al. 319-21).

Regarding the delivery of mental healthcare, multiple models exist. From a macro-perspective, organizations and governments can implement population-based interventions to reduce the chances of developing an illness, such as enacting public policies or conducting educational campaigns for mental wellness. In primary care offices, clinicians intermittently screen for early signs of developing mental health conditions; for example, pediatricians and family physicians might provide a questionnaire to their patients screening for symptoms of depression (Wissow 
et al. 1134-35). When conditions are not caught at an early stage in this manner and subsequently worsen - which occurs in a majority of cases - patients will present to a mental health provider for specialized treatment (Bijl and Ravelli 603-06; Olfson et al.). These providers are academically trained healthcare professionals such as psychologists, psychiatrists, social workers, and licensed family therapists; the training involved typically produces knowledgeable providers but is also rigorous, expensive, and time-consuming (Kakuma et al. 1655-59; Magen and Banazak 198-200; Zisook et al.; Boggs and Douce 674-78).

Multiple studies have strengthened the credibility of the biopsychosocial model, for instance by showing how physical phenomena directly impact our psychological states, and how our psychological states impact our physical wellbeing (e.g., Kong et al.; Pennebaker and Skelton 526-8). Using the biopsychosocial formulation and the medical model of illness, modern psychiatric practice has benefited millions of individuals across the globe and helped to destigmatize populations who were previously at great risk of morbidity and mortality (Saxena 496-7; Singla et al.). Systems of care delivery and practice, too, have been effective in treating problems at differing levels of severity, especially in treating individual cases (Singla et al.). These frameworks for conceptualization and practice, therefore, have significant strengths.

Yet, with the surges in mental health challenges during the COVID-19 pandemic and the lack of ability to meet these needs, it is important to examine where the current frameworks fall short as well. The following points highlight a few limitations demonstrated by these frameworks. First, the frameworks cannot address some of the major psychological factors affecting individuals during the course of the pandemic, including existential questions such as the creation of meaning and purpose in suffering. Second, these frameworks examine strengths and vulnerabilities primarily within individuals and are unable to recognize challenges or suggest solutions on scales involving entire communities or populations which the pandemic has affected. Third, as an extension of the second example, while these frameworks and care systems are often useful tools when prevalence is low, they are essentially focused on the diagnosis and treatment of individuals and are not equipped to meet population-level challenges when the need expands. The following sections discuss these limitations in further detail.

\section{THe Loss OF Hope}

The COVID-19 pandemic is, in our time, a global event of tremendous scale akin to infectious outbreaks and disasters of the distant past. As such, it shares some characteristics with largescale natural disasters or humanitarian crises in which many individuals suffer suddenly and simultaneously.

In the psychological literature, trauma is described as occurring when 
individuals experience disturbing and uncontrollable events that typically involve fear for safety or security and which often challenge their view of the world as a just, safe, and predictable place; examples of traumatic events include sexual violence, assault, natural disasters, war, or sudden accidents (American Psychological Association). Of course, a global event such as the COVID-19 pandemic has no singular perpetrator such as in the case of many individualized traumatic events, and the scars left by the pandemic may be vastly different than for survivors of rape or physical assault. Still, the pandemic shares a number of psychological elements with trauma which cannot be ignored: the inability to feasibly escape the prompting situation; feelings of helplessness and loss of power and control; sudden removal of safety; and the perceived betrayal of an established social compact in which individuals are able to protect each other from harm (Herman 51). A global inability to contain the infection, coupled with the sudden decline and death of millions of individuals, have left countless souls with the very emotions of helplessness, loss of control, vulnerability, and betrayal that can characterize trauma. In addition, as articulated in "hopelessness theory" and demonstrated experimentally, when individuals have little control over negative events which they perceive to be long-lasting, unchangeable, and global, they are at higher risk of developing hopelessness (Seligman 407-11; Abramson 359-64). Hopelessness is a well-demonstrated risk factor for suicide, a symptom of major depressive disorder, and a factor leading to ineffective coping strategies such as increased substance use and greater consumption of electronic media (Ribeiro et al. 281-85; Case and Deaton 133-47; Abramson 360-04). We have seen increasing reports of hopelessness, substance use, electronic media usage, and suicidal ideation emerge during this pandemic (Banerjee et al. 2-3; Statistics Canada; Wong et al. 34).

For those undergoing intense suffering, the establishment of resilience and hope can often rely on an important process: the finding of meaning in suffering (Egnew 171-73; Neimeyer 9-22; Frankl 116). While the biopsychosocial framework can assist in some important ways, it unfortunately cannot address deep, intangible questions such as those of building meaning or finding purpose. New forms of psychotherapy developed within the current framework to help bring meaning out of negative experiences appear to be no more efficacious than other current treatments (D'Souza and Rodrigo; Pearce and Koenig). While the most promising such psychotherapy, Acceptance and Commitment Therapy, emphasizes relief from suffering and coherence among one's goals and actions, it relies upon an individual's existing value systems rather than the finding of meaning itself (Hayes et al. $1-5)$. 


\section{FACTORS OUTSIDE THE INDIVIDUAL}

Furthermore, because the biopsychosocial formulation of mental illness is only able to identify social-environmental factors which operate immediately around the individual, it often cannot address the primary causes of such factors. For example, even prior to the COVID-19 pandemic, many across the world lacked safe places to shelter, to cook, to collect clean and potable water, or to learn, conditions which have been worsened by the loss of income and housing, closure of schools, and the strain on public services (Marmot and Wilkinson 6-30; Nicola 186-90; Marmot et al. 1662-68; Jones and Grigsby-Toussaint 1-3; Laborde et al. 501-02; Van Lancker and Parolin 243). Due to dwindling financial resources, opportunities for some communities have disappeared that may not reemerge post-pandemic (Baldwin and Weder di Mauro 45-52; Jones and Grigsby-Toussaint 1-3). Communal spaces-youth centers, community gardens, gatherings for prayer and devotion - can create social support and a sense of belonging and serve as vital defenses against the effects of chronic stress, isolation, and hopelessness during the pandemic (Kingsbury 129497); unfortunately, due to the impact of infection and the resulting control measures, these community spaces are now significantly limited, particularly in communities with low rates of vaccination (Flint et al. 1114-15; Bethke and Wolff 366-69).

Thus, while the biopsychosocial framework might recognize specific factors such as community spaces as helpful tools to build resilience against the development of mental illness, it does not have anything to say about the state of the community itself and cannot therefore provide adequate solutions when such environments are not available. Due to its focus on the individual, the biopsychosocial framework might not recognize these key social-environmental factors impacting mental resilience or vulnerability. If a model's scope is such that it cannot incorporate all contributing variables, it will not be able to address them properly.

\section{LACK OF ACCESS to CARE}

Due to the current conceptual framework of mental illness as an individual phenomenon, the resultant practice models have never been able to adequately meet global needs. Population-based interventions, rather than viewed as collective investments in current and future health, tend to be few and poorly funded (GBD; Eaton et al. 1594-601; Alloh et al. 12-13). Many people, facing supply-and-demand models of care designed for commercial markets, either have no primary care provider to offer mental health screenings or simply cannot present to their clinic with adequate frequency (Rhodes et al. 863-66; Wissow et al. 1134-35). As a consequence, mild symptoms develop into difficult-to-treat disorders requiring the aid of mental health specialists. Yet, due to the high barriers to entry for 
the training of such specialists, these providers are quite scarce; globally, there is less than one mental health professional for every 100,000 people (GBD; Andrilla et al. S201-03). In resource-poor communities, this number is still lower (GBD). In short, systems of support and care for the mentally ill have been sorely lacking. Even prior to the pandemic, in low- and middle-income countries, between seventy-six and eighty-five percent of people with mental health conditions received no treatment for their condition (GBD; Saraceno and Dua S112-13).

This individually focused care system is unable to predict or prevent massive surges in need such as that precipitated by the COVID-19 pandemic. In a healthcare system in which wait times for a mental health specialist can already be months, a seven-fold increase in depression rates will likely cause further delays in treatment.

This is, of course, not to cast blame on medical or governmental institutions. In fact, over the past few decades prior to the pandemic, many organizations and legislative bodies have attempted to craft a patchwork of solutions to the above challenges, involving policy changes, advocacy campaigns, and efforts at increasing the distribution of limited resources in a more just fashion - a longstanding ideal within medical ethics (Eaton et al. 600-02; Alloh et al. 15-16).

\section{TOWARD AN INTEGRATIVE Framework}

It is clear that discrete limitations in a framework for conceptualizing and treating mental illness, such as the inability to address questions of meaning or purpose and focusing on the individual and their immediate surroundings in both the assessment and treatment process, can have an enormous impact on global outcomes - an impact that is only exacerbated by the ongoing pandemic. In order to meet the rising needs and more comprehensively address the factors involved, this paper proposes to add to the existing framework several new dimensions. It will be helpful to start by considering the nature of human reality and thought.

The field of neuroscience, while able to discover daily insights into the functional anatomy of the brain, has been thus far unable to solve the puzzle of how our minds produce arguably the most important function: thought itself. Regarding the nature of the human being and the reality of thought, the Writings of the Bahá'i Faith provide a rich body of knowledge from which to draw. 'Abdu'l-Bahá informs us that the "human spirit which distinguishes man from the animal" is the "rational soul," which "discover[s] the realities of things, comprehend[s] their properties," and from which emanates the mind ('Abdu'l-Bahá, Some Answered Questions 58:3). Thus, from the perspective of the Bahá'í writings, human reality is in essence a spiritual one.

Here, it is important to define what is meant by "spiritual" in the context 
of the Bahá'i writings. 'Abdu'l-Bahá states that humankind is composed of both a material reality and a non-material, or spiritual, one which sustains it and is divine in nature; the immortal soul, our spiritual reality, is "entirely out of the order of physical creation" ('Abdu'l-Bahá, Paris Talks 29:13). Each of these components, the material and the spiritual, has distinct capacities that can be developed during one's lifetime (Bahá'u'lláh, Gleanings 68). While physical, or material, capacities can be developed through the provision of basic needs and the training of skills and physical abilities, spiritual capacities can be realized through the nurturing of the intellect with education, the carrying out of will through action, and the development of virtuous qualities through practices such as prayer and service to humankind (Bahá'u'lláh, Gleanings 262; 'Abdu'l-Bahá, Some Answered Questions 157, 230-1). "Spirituality," in this way, can be seen as the process of developing one's spiritual capacities, the recognizing of one's non-material nature, and the practicing of virtuous qualities. While the term "spirituality" in the Bahá'í Writings can also refer to a person's sense of connection with God or include the practice of praying for departed souls, the Bahá'í Writings primarily does not define this term as pertaining to external beings acting upon us, but instead as descriptions of our inner nature and capabilities.

Regarding the mind, 'Abdu'l-Bahá explains further that it "is the power of the human spirit. Spirit is the lamp; mind is the light which shines from the lamp" ('Abdu'l-Bahá, Some Answered Questions 58:4). Our minds, therefore, are also of a spiritual nature; conscious thought arises from the reality of our spirit. Because our thoughts drive our actions in the material world via the brain and the body, we can say that our spiritual reality shapes our material reality.

Shoghi Effendi confirms this, describing more concretely a connection between the spiritual and material: "the mind forms a link between the soul and the body, and the two interact on each other" (Arohanui 89). In the Bahá'í perspective, our spiritual existence provides an impetus for our brain's conscious thoughts - and therefore our emotions, our behavior, and our very mental health. Likewise, Shoghi Effendi's statement makes it clear that this connection is bidirectional; just as our mind, a spiritual entity, impacts our physical reality, our actions in the world impact our spiritual reality. In this way, the Bahá'í Writings are consistent with some of the most dominant theories in clinical psychology, such as the cognitive-behavioral model wherein thoughts, emotions, and behaviors continually influence one another in bidirectional cycles.

In his study of human nature and mental health, psychologist and Bahá'í scholar Michael Penn succinctly describes three interacting processes which form and shape human identity. He identifies them as "(1) compositional and evolutionary processes, which include biological and genetic 
influences (nature); (2) social processes, which include experiential, educational, and cultural forces (nurture); and (3) innate processes associated with the life, development, and activity of the human soul or spirit" (30).

Human thought is influenced by spiritual forces operating within and around us. But this is not the only channel through which spiritual forces exert themselves. In fact, the Bahá'í Writings allow us to recognize that spiritual processes are continually shaping our existential world in direct and indirect ways. These processes act on all things, from the expression of individual virtue to the values of an entire culture or the priorities of international bodies. When a community, an organization, or a culture expresses - or fails to express - spiritual realities such as the oneness of humankind, there is a direct effect on individuals' resilience or vulnerability to mental illnesses. As an example, when extreme poverty and hunger persist across multiple generations - a result of societal value judgments shaped by neglect of the inherent nobility of each individual human being - epigenetic changes occur which affect the biology of future generations and increase the risk of developing mental health challenges (Bahá'u'lláh, Arabic Hidden Words no. 13, n. 22; Kaati et al. 786; Mathers et al.). Likewise, the growing educational, social, and economic disparities which exist between marginalized and privileged populations in many places across the world - also resulting from the lack of acknowledgement of the oneness of humankind, or of an adequate expression of the values of justice or generosity-impact the risk of developing mental illnesses (Marmot et al. 1662-63). We can see, therefore, that spiritual processes are in fact intertwined with each of the biological, psychological, and social-environmental components that contribute to our mental wellness or illness.

A Bahá'í conceptualization, then, can add to the prevailing biopsychosocial framework a new, spiritual dimension. When seeking to understand the development of a mental health condition in an individual, we must consider the spiritual forces at play within them, around them, and in society itself.

This is not to say that mental health conditions are ailments of the soul or one's character. In keeping with psychological and biomedical research, the Bahá'í Writings tell us that mental health conditions are in reality conditions of the physical body. Bahá'u'lláh states explicitly that "the soul of man is exalted above and is independent of all infirmities of body or mind" (Gleanings 80:2). Thus, while spiritual processes at work within an individual and in the society around them can contribute to the development of illness in the brain, the soul itself is unaffected. Regarding the integrity of the soul for those affected by mental illness, 'Abdu'l-Bahá states further:

Now concerning mental faculties, they are in truth of the inherent properties of the soul, even as the radiation of light is the essential 
property of the sun. The rays of the sun are renewed but the sun itself is ever the same and unchanged. Consider how the human intellect develops and weakens, and may at times come to naught, whereas the soul changeth not. (““Abdu'l-Bahá's Tablet”)

Still, just as mental health can be affected by intangible forces acting on the world around us, and even though mental illness is not a spiritual phenomenon, the Universal House of Justice informs us that "its effects may indeed hinder and be a burden in one's striving toward spiritual progress" (15 Jun. 1982). Because mental health conditions manifest themselves in our perceptions, thoughts, emotions, and actions, they can serve as a veil between us and the virtues toward which we strive. For example, the condition of major depressive disorder can present with symptoms of slowed cognition, alterations in perception, and a decline in social interest leading to withdrawal from friends and loved ones. These symptoms can prevent an afflicted person from engaging in learning, service, habits of personal wellness, and the practice of virtuous actions which can raise personal and spiritual capacities.

Other researchers have also begun to recognize the need to incorporate spirituality into a mental model, and some have begun proposing such models (e.g., Sulmasy 27). However, these models portray spiritual factors mainly as a set of conscious religious experiences and value systems, or a quantification of religiosity; in other words, they often present spiritual factors as a subset of a person's cultural viewpoints rather than recognizing that spiritual processes are independent and act upon each of the biopsychosocial factors in an individual's health. Also, significantly, a number of non-Western indigenous frameworks for understanding and treating mental illnesses, such as those developed by First Nations and South Asian communities, have long incorporated a spiritual dimension in both mental and physical health (Hatala 8-11; Brown 34-36; Isaak et al. 350-55; Trivedi 18-20). While these conceptualizations are numerous and varied, perhaps one common theme is the recognition of a spiritual self and the need for integration between the spiritual and material identities; here there may be some overlap between these frameworks and a Bahá'i-inspired framework (Fleming and Ledogar 3-9; Hatala 8-11). It would be wise for scholars and mental health practitioners serving such populations to learn more about these conceptualizations, both to better serve their patients and also to reexamine the validity of our current frameworks in various contexts.

\section{The Finding of Meaning AND HoPE}

A framework involving the observation of spiritual processes can allow us to utilize spiritual solutions which the prevailing framework cannot. One example is addressing the unsolved problem of finding meaning in suffering. 
For us to create meaning from suffering, it is useful to consider meaning beyond suffering itself, in the very lives we lead as individuals and as a collective society. The writings of Bahá'u'lláh and 'Abdu'l-Bahá touch on these topics of meaning and purpose. They assert that the purpose and meaning of life, on an individual level, lie in the recognition of God and spiritual reality, and in the development of our souls through the acquisition and practice of virtue; and that on a collective level, they lie in the building of bonds of love and the promotion of an ever-advancing civilization ('Abdu'l-Bahá, Foundations 63; Bahá'u'lláh, Gleanings 109:2). Bahá'u'lláh explains that knowledge of the self is essential: "The first Taraz and the first effulgence which hath dawned from the horizon of the Mother Book is that man should know his own self and recognize that which leadeth unto loftiness or lowliness, glory or abasement, wealth or poverty" (Tablets 4:7). When experiencing events of either joy or great pain, the individual can reflect upon what leads to their lowliness or loftiness in order to examine how they are being affected and determine what they might do next.

The Bahá'í Writings can assist us, too, in understanding the meaning and purpose of suffering. In the Hidden Words, Bahá'u'lláh tells us, "My calamity is My providence, outwardly it is fire and vengeance, but inwardly it is light and mercy" (Persian n. 51). Shoghi Effendi eloquently observes in a letter to a believer that "suffering, although an inescapable reality, can nevertheless be utilised as a means for the attainment of happiness," that it is "both a reminder and a guide" (Unfolding Destiny 434). 'Abdu'l-Bahá explains that events such as the ones we witness in these times can have an ultimately spiritual purpose:

Do not grieve at the afflictions and calamities that have befallen thee. All calamities and afflictions have been created for man so that he may spurn this mortal world-a world to which he is much attached. When he experienceth severe trials and hardships, then his nature will recoil and he will desire the eternal realm - a realm which is sanctified from all afflictions and calamities. (Selections 197:1)

These writings emphasize that a primary purpose of suffering is the recognition of our spiritual natures. Afflictions on the body of humankind, then, can cause us to bring our attention from a transient material reality to the more significant spiritual reality and therefore help us to develop our spiritual capacities. In this way, the purpose and meaning of human life, according to the Bahá'í Writings, are perhaps more accessible to us during times of suffering, and suffering can indeed help us orient toward this purpose and meaning.

In another letter, Shoghi Effendi makes it clear that crises are in fact necessary and indispensable components of the spiritual development of 
both individuals and human civilization as a whole:

You seem to complain about the calamities that have befallen humanity. In the spiritual development of man a stage of purgation is indispensable, for it is while passing through it that the over-rated material needs are made to appear in their proper light. . . . The present calamities are parts of this process of purgation, through them alone will man learn his lesson. They are to teach the nations, that they have to view things internationally, they are to make the individual attribute more importance to his moral than his material welfare. (14 Oct. 1931, qtd. in Hornby no. 441)

From writings such as these, and from the writings of other world Faiths, we can understand that there might indeed be a greater meaning and purpose to our suffering, both individual and collective. By reminding us of this purpose, a spiritually informed framework can allow suffering to bring us toward a pattern of living that integrates the development of both our physical and spiritual capacities - rather than casting suffering solely as a risk factor for the development of physical and mental illnesses.

In addition, a framework that helps to maintain a sense of meaning can also reduce the consequences of hopelessness on our population; meaning breeds hope, which for many can help to prevent suffering from developing into illness (Ribeiro et al. 283-85). Psychological research has shown that the creation of meaning in suffering and trauma can greatly assist in the process of healing from it (Edwards and Van Tongeren 725-30; Egnew 171). Some researchers have even been developing scales of spiritual meaning to assist clinical efforts in this direction, although these have not been widely utilized (e.g., Mascaro et al. 848).

Although it is beyond the scope of this paper to detail recommendations for clinical practice, one can see how this spiritually informed framework could serve as an invaluable tool for practitioners serving patients who are struggling with this question of meaning in suffering. Any such practitioner would want to be aware of several points, of course: First, meaning can be simultaneously both transcendent and personal; in other words, while this framework proposes that ultimate meaning and purpose are spiritual and that suffering can in fact reveal such meaning, each individual seeking meaning and purpose in the context of the COVID-19 pandemic has a unique story and a particular perspective, which can also have a significant impact on their understanding of current and past events and which should be nurtured by a mental health provider. Second, mental health providers must seek to avoid bias, discrimination, and coercion in their treatment of patients, such as the implication that quality of care is dependent on a patient adopting a particular set of spiritual beliefs (American Psychiatric Association 
3-4). Any implementation of this spiritually informed framework would need to be performed with the informed consent of a patient, and while the practitioner may guide the patient toward new understandings of meaning and purpose through their treatment, care must be taken to avoid imposing the clinician's own beliefs onto the patient.

It is important to note that transformation of pain into meaning is not the same as denial of pain. When experiencing chronic stress, isolation, and psychological suffering in the wake of the pandemic, it is not useful to minimize these factors, nor to rely upon a fragile optimism that they will simply vanish. Rather, one benefits from first acknowledging the suffering, grieving these changes, and seeking to find meaning and purpose.

Of course, many who read spiritual texts and already have a developed sense of meaning are still suffering from mental health decline during the pandemic. Such individuals might seek to build upon their current understanding of meaning or seek to learn from that of others.

\section{OUTSIDE THE INDIVIDUAL: The Three Protagonists}

This paper has thus far described how examining the spiritual dimensions of biological, psychological, and social-environmental factors can assist us in combating the mental health challenges exacerbated by the current pandemic. Still, as elaborated earlier, we know that the social and psychological components of mental health and illness do not occur only within the vacuum of an individual and their direct environment. Indeed, enmeshed and intertwined social ills such as lack of affordable housing, unequal distribution of quality education, and discriminatory and prejudicial practices significantly impact mental health (Burns 108-10; Marmot et al. 1663-66). Each of these, of course, is affected by spiritual forces; thus, social ills can be seen as spiritual ills, and spiritual principles at the level of community are needed to resolve these challenges. Spiritual ills at the level of institutions impact mental health too, such as the unjust delivery of healthcare, laws and policies that provide preferential advantages, and organizations that drive consumerism by promoting feelings of low self-worth (Cook et al.). We learn from Shoghi Effendi that "man is organic with the world. ... The one acts upon the other and every abiding change in the life of man is the result of these mutual reactions" (qtd. in Compilation 84).

We can take our spiritually informed framework of the biopsychosocial model of mental illness further, then, to acknowledge that mental health, just like other realities, is influenced by the whole of society. To be complete, an effective framework must integrate individual factors with these broader societal influences. One way to do this is to examine the three actors that make up human society: other individuals, the community, and our institutions.

The Universal House of Justice writes of these three social actors-which 
Bahá'ís have come to term the "three protagonists"-in its Ridván 2012 message that "relations among the three corresponding actors in the world at large - the citizen, the body politic, and the institutions of society-reflect the discord that characterizes humanity's turbulent stage of transition" (2). Given the still-present stigma toward mental health conditions within communities and the low public trust in established institutions of government, economy, and healthcare around the globe, how accurate this is proving to be now regarding the mental health of the world's population (Hosking 77-86; Rüsch et al. 530-32; Shore 4-7).

Bahá'u'lláh also references the need for the integration of various actors in the healing of the world's current challenges, telling us to "regard ye the world as a man's body, which is afflicted with divers ailments, and the recovery of which dependeth upon the harmonizing of all its component elements" (Bahá'u'lláh, Summons 『152). We must realize that our mental health challenges are not simply the problems of many individuals but rather problems involving our collective community. Under the prevailing framework for mental illness and treatment, a prescription is offered at the level of the individual. What we need are prescriptions at the levels of the community and institutions as well.

\section{Addressing Access to CARE}

Here, this paper will provide a few brief suggestions for how an integrative, spiritually informed framework can better address the lack of access to mental health treatment, a major limitation of the current model. Institutions of medicine and government play a large part in setting priorities for funding research and clinical care, promoting or preventing opportunities for training, and assessing the efficiency of current practices. Despite the clear impact of mental health conditions on populations, little funding has thus far been dedicated to mental health research or the expansion of clinical services. On average, less than two percent of countries' health budgets is allocated to the treatment of mental health conditions (GBD). In addition, problems of large-scale poverty and poor literacy still impact access to care and result in poor mental health outcomes (Lynch and Kaplan; Backlund et al. 1377-80).

This framework acknowledges how such institutional prioritization contributes to the development of mental illness, and that no amount of individual treatment will be sufficient without correcting this problem. It recognizes that governments and institutions of healthcare have a duty to establish clear priorities for increasing access to care for those who do not receive it and for those who are at highest risk. This might include: assessing efficacy of current funding; examining and balancing other expenditures; establishing internationally agreed-upon measurement tools to ensure broader segments of the population are screened; and preparing potential resources should future surges of mental illness occur. 
In understanding the global mental health challenges as a problem of community and not just individuals, this framework also recognizes the vital role that communities must play in increasing access to care. Indeed, in present-day society, especially in individualistic cultures, the community as an actor in social and spiritual progress has often been overlooked as inconsequential compared to the power of individuals and institutions. When calamity occurs and when access to immediate social support is more limited, we have an opportunity to see a cherishing of community as a spiritually and materially powerful force in the shaping of our lives.

Communities across the globe, assisted by specific institutions with enough resources, can implement health strategies which have already been effective on smaller scales, and which could fill the gap left by the worldwide scarcity of mental health specialists (Kola 656-57). One main way in which communities can do this is to train lay health workers to deliver mental healthcare. This process, called "task-shifting," has previously helped to meet the needs in regions where little or no care existed. With a flexible workforce of local, trusted individuals, stigma can be reduced, mental healthcare can be sought more frequently, and workers can serve within a number of settings such as homes, schools, workplaces, and care centers (Kohrt et al. 10-15). Communities, perfectly poised to provide solutions such as this, can vastly reduce the problem of mental health access if task-shifting is broadly implemented. Clinical guides already created by the World Health Organization (mhGAP) and other organizations can assist in the training of these workers and the implementation of such strategies.

In order to bolster resilience against the development and progression of mental health challenges, communities can also implement strategies that go beyond healthcare itself. In light of a spiritually informed framework, these efforts could focus on: the development of strong and extensive networks of support for individual community members; the strengthening of communal spaces; the provision of basic resources for the mitigation of various risk factors; the offering and support of spiritual education and practice; the nurturing of opportunities for service; and the creation of spaces to discuss and learn about factors contributing to mental health and illness more directly. While it is certainly a challenge to implement such measures - during and emerging from the lockdown - as have been needed for immediate safety, communities can strive to enact creative approaches such as the use of virtual gatherings, individual visits among community members at safe distances, and the sharing of visual, musical, and written media as rich means of communication and collaboration. As one example, the Bahá'í world community has been undergoing a process of learning and practice in its community-building endeavors, both prior to and during the pandemic, which could 
serve as a model or a starting point for other communities around the globe. Such endeavors often start with a small cohort of individuals spending time and effort gaining an understanding of the conditions, strengths, and challenges of their local communities; then, in consultation with each other and with like-minded community members, they initiate various short- or long-term activities meant to address such challenges. These may include teaching groups for children and youth meant to develop moral perception and become active protagonists within communities; organizing gatherings for prayer, community discussion, and deepening on issues of import; visiting various community members to enhance bonds of friendship and support; and creating spaces for training of others on paths of service to community. As these endeavors organically grow, opportunities arise to address specific mental health needs. These efforts can go a long way toward building resiliency factors within communities. Importantly, the Bahá'i framework for community-building operates within a mode of learning and utilizes a high degree of flexibility, as conditions are ever-changing.

It becomes clear, then, that we need an integrated framework which understands the spiritual contributions to our current crisis and which can offer insights at the levels of communities and institutions, as well as individuals.

\section{CONCLUSION AND}

\section{Future Directions}

In this phase of humankind's collective evolution, we are becoming acutely aware of the interconnected forces involved in our rising mental health challenges and the need for an integrative, spiritually informed approach. The COVID-19 pandemic and resulting lockdowns have created an ever-changing psychological landscape, one to which we must readily adapt. In the interests of both scholarship and practical need, this author invites like-minded scholars to examine this framework and any others which might be able to meet the challenges of the present pandemic.

Further work is needed during this critical time. First, as an application of this conceptual framework, this author intends to examine in more detail the major elements related to the three societal actors-individuals, communities, and institutions - which have contributed to our present mental health challenges, and hopes to publish any findings. Of course, as these factors are numerous and intertwined, any single study of such factors would likely be incomplete; again, this author invites others to collaborate and contribute to this growing body of knowledge.

Second, as these factors are determined, it is just as important to implement action to address these factors at all the relevant societal levels. This author invites discussion on this topic. Any real solutions will likely require dedication, perseverance, and intense cooperation. 
Third, as there exist multiple conceptual frameworks for understanding psychological phenomena across cultures and traditions, this work can be significantly supplemented with a more thorough investigation into the other frameworks which incorporate a spiritual dimension. For example, several non-Western frameworks for mental health and illness should be further studied and examined alongside the framework presented here to better understand and meet rising mental health needs.

Perhaps this is one of many inflection points in the trajectory of our global civilization, one in which the world can turn to the wisdom of the Bahá'í writings and look to the examples within its communities and institutions. Ultimately, as the shockwaves of this series of global events are still reverberating, it will be the work of individuals across the world, communities they form, and institutions they build to act and together develop a new, sustainable system of mental healthcare for the global population in years to come.

\section{WORKS CITED}

'Abdu'l-Bahá. “'Abdu'l-Bahá's Tablet to Dr. Forel." August Forel and the Bahá'i Faith, by John Paul Vader, George Ronald, 1978, pp. 70-80.

. Foundations of World Unity.

U.S. Bahá'í Publishing Trust, 1979.
___ Paris Talks. 11th ed., U.K. Bahá'í Publishing Trust, 1972. Bahá'i Reference Library. bahai.org/library/authoritative-texts/abdul-baha/paris-talks/

Selections from the Writings of 'Abdu'l-Bahá. Bahá'í World Centre, 1982. Bahá'i Reference Library. bahai.org/ library/authoritative-texts/ abdul-baha/selections-writings-abdul-baha/.

Some Answered Questions. Translated by Laura Clifford Barney, rev. ed. Bahá'i Reference Library. bahai.org/ library/authoritative-texts/ abdu l-baha/some-an swered-questions/.

Abramson, L. Y., et al. "Hopelessness Depression: A Theory-Based Subtype of Depression." Psychological Review, vol. 96, 1989, pp. 358-72. doi:10.1037/0033295X.96.2.358.

Alloh, F., et al. "Mental Health in Lowand Middle-Income Countries (LMICs): Going beyond the Need for Funding." Health Prospect, vol. 17, no. 1, 2018, pp. 12-17. doi:10.3126/hprospect.v17i1.20351.

Ambaw, Fentie, et al. "Incidence of Depression in People with Newly Diagnosed Tuberculosis in Ethiopia: A Cohort Study." Global Mental Health, vol. 7, 2020, pp. 1-9. doi:10.1017/gmh.2019.27. 
American Psychiatric Association. The Principles of Medical Ethics: With Annotations Especially Applicable to Psychiatry. 2013 ed.

American Psychological Association. "Trauma." 2020. dictionary.apa.org/trauma.

Andrilla, C. Holly A., et al. "Geographic Variation in the Supply of Selected Behavioral Health Providers." American Journal of Preventive Medicine, vol. 54,6, 2018, pp. S199-207. doi:10.1016/j.ampepre.2018.01.004.

Ayuso-Mateos, José L., et al. "From Depressive Symptoms to Depressive Disorders: The Relevance of Thresholds." British Journal of Psychiatry, vol. 196, no. 5, 2010, pp. 365-71.

Backlund, E., et al. "A Comparison of the Relationships of Education and Income with Mortality: The National Longitudinal Mortality Study." Social Science \& Medicine, vol. 49, no. 10, 1999, pp. 1373-84. doi:10.1016/s02779536(99)00209-9.

Bahá'u'lláh. Gleanings from the Writings of Baháu'lláh. Translated by Shoghi Effendi. Bahá'í Publishing Trust, 1994. Bahá'í Reference Library. bahai.org/ library/authoritative-texts/bahaullah/gleanings-writings-bahaullah/

__ . The Summons of the Lord of Hosts. Baha' i Reference Library. bahai.org/ library/authoritative-texts/bahaullah/summons-lord-hosts/

. Tablets of Baháu'lláh Revealed after the Kitáb-i-Aqdas. Translated by Habib Taherzadeh et al. Bahá'i Reference Library. bahai.org/library/authoritative-texts/bahaullah/tablets-bahaullah/.

___ The Hidden Words of Bahá'u'lláh. Translated by Shoghi Effendi. Bahá'í Publishing Trust, 1985.

Baldwin, Richard, and Beatrice Weder di Mauro. Economics in the Time of COVID-19. Centre for Economics Policy Research Press, 2020.

Banerjee, Debanjan, et al. "The Dual Pandemic' of Suicide and COVID-19: A Biopsychosocial Narrative of Risks and Prevention." Psychiatry Research vol. 295, 2021, pp. 1-8. doi:10.1016/j.psychres.2020.113577.

Bethke, Felix S., and Jonas Wolff. "COVID-19 and Shrinking Civic Spaces: Patterns and Consequences." Zeitschrift fur Friedens- und Konfliktforschung, vol. 9, 2020, pp. 363-74. doi:10.1007/s42597-020-00038-w.

Bijl, Rob V., and Anneloes Ravelli. "Psychiatric Morbidity, Service Use, and Need for Care in the General Population: Results of the Netherlands Mental Health Survey and Incidence Study." American Journal of Public Health, vol. 90, no. 4, 2000, pp. 602-07.

Bitew, Tesera. "Prevalence and Risk Factors of Depression in Ethiopia: A Review." Ethiopian Journal of Health Sciences, vol. 24, no. 2, 2014, pp. 16169. doi:10.4314/ejhs.v24i2.9.

Blanco, Carlos, et al. "Risk Factors for Anxiety Disorders: Common and Specific Effects in a National Sample." Depression and Anxiety, vol. 31, no. 9, 2014, pp. 756-64. 
Boggs, Kathleen R., and Louise A. Douce. "Current Status and Anticipated Changes in Psychology Internships: Effects on Counseling Psychology Training." The Counseling Psychologist, vol. 28, no. 5, 2000, pp. 672-86.

Borrell-Carrió, Francesc, et al. "The Biopsychosocial Model 25 Years Later: Principles, Practice, and Scientific Inquiry." Annals of Family Medicine, vol. 2, no. 6, 2004, pp. 576-82.

Brodal, Per. The Central Nervous System: Structure and Function. 3rd ed. Oxford UP, 2004.

Brown, Ron. "Australian Indigenous Mental Health." Australian and New Zealand Journal of Mental Health Nursing, vol. 10, no. 1, 2008, pp. 33-41. doi:10.1046/j.1440-0979.2001.00189.x.

Bueno-Notivol, Juan, et al. "Prevalence of Depression during the COVID-19 Outbreak: A Meta-Analysis of Community-Based Studies." International Journal of Clinical and Health Psychology, vol. 21, no. 1, 2021. doi:10.1016/j.ijchp.2020.07.007.

Burns, J. K. "Poverty, Inequality and a Political Economy of Mental Health." Epidemiology and Psychiatric Sciences, vol. 24, no. 2, 2015, pp. 107-13.

Cacioppo, Stephanie, et al. "Loneliness: Clinical Import and Interventions." Perspectives on Psychological Science: A Journal of the Association for Psychological Science, vol. 10, no. 2, 2015, pp. 238-49.

"Toward a Neurology of Loneliness." Psychological Bulletin, vol. 140, no. 6, 2014, pp. 1464-504.

Case, Anne, and Angus Deaton. Deaths of Despair and the Future of Capitalism. Princeton UP, 2020.

Compilation of Compilations, vol. 1. Bahá'í Publications Australia, 1991.

Cook, Benjamin L., et al. "Racial/Ethnic Disparity Trends in Children's Mental Health Care Access and Expenditures from 2002 to 2007." Health Services Research, vol. 48, no. 1, 2013, pp. 129-49.

Dobson, Keith S., and David J. A. Dozois. Risk Factors in Depression. Elsevier, Inc., 2008.

D’Souza, Russell F., and Angelo Rodrigo. "Spiritually Augmented Cognitive Behavioural Therapy." Australasian Psychiatry: Bulletin of Royal Australian and New Zealand College of Psychiatrists, vol. 12, no. 2, 2004, pp. 148-52. doi:10.1080/j.1039-8562.2004.02095.

Eaton, Julian, et al. "Scale Up of Services for Mental Health in Low-Income and Middle-Income Countries." The Lancet, vol. 378, no. 9802, 2011, pp. 1592-603. doi:10.1016/S0140-6736(11)60891-X.

Edwards, Megan E., and Daryl R. Van Tongeren. "Meaning Mediates the Association between Suffering and Well-being." The Journal of Positive Psychology, vol. 15, no. 6, 2019, pp. 722-33. doi:10.1080/17439760.2019.1651890.

Egnew, Thomas R. "Suffering, Meaning, and Healing: Challenges of Contempo- 
rary Medicine." The Annals of Family Medicine, vol. 7, no. 2, 2009, pp. 170-5. doi:10.1370/afm.943.

Engel, George L. "The Clinical Application of the Biopsychosocial Model." The American Journal of Psychiatry, vol. 137, no. 5, 1980, pp. 535-44. doi:10.1176/ajp.137.5.535.

Fenster, Robert J., et al. "Brain Circuit Dysfunction in Post-Traumatic Stress Disorder: From Mouse to Man." Nature Reviews Neuroscience, vol. 19, no. 9, 2018, pp. 535-51.

Fleming, John, and Robert J. Ledogar. "Resilience and Indigenous Spirituality: A Literature Review." Pimatisiwin, vol. 6, no. 2, 2008, pp. 47-64.

Flint, Alastair J., et al. "Effect of COVID-19 on the Mental Health Care of Older People in Canada." International Psychogeriatrics, vol. 32, no. 10, 2020, pp. 1113-6. doi:10.1017/S1041610220000708.

Frankl, Victor. Man's Search for Meaning: An Introduction to Logotherapy. 4th ed., Beacon Press, 1992.

Freedheim, Donald K., and Irving B. Weiner. Handbook of Psychology, Volume I: History of Psychology. John Wiley \& Sons, Inc., 2003.

Gabrielli, Joy, and Emily Lund. "Acute-on-Chronic Stress in the Time of COVID-19: Assessment Considerations for Vulnerable Youth Populations." Pediatric Research, vol. 88, 2020, pp. 829-31. doi:10.1038/s41390020-1039-7.

GBD 2017 Disease and Injury Incidence and Prevalence Collaborators. "Global, Regional, and National Incidence, Prevalence, and Years Lived with Disability for 354 Diseases and Injuries for 195 Countries and Territories, 1990-2017: A Systematic Analysis for the Global Burden of Disease Study 2017." The Lancet, vol. 392, no. 10159, 2018, pp. 1789-858.

Griesinger, Wilhelm. Mental Pathology and Therapeutics. New Sydenham Society, 1867.

Hatala, A. R. "Spirituality and Aboriginal Mental Health: An Examination of the Relationship between Aboriginal Spirituality and Mental Health." $A d-$ vances in Mind-Body Medicine, vol. 23, no. 1, 2008, pp. 6-12.

Hayes, Steven C., et al. "Acceptance and Commitment Therapy: Model, Processes, and Outcomes." Behavioral Research and Therapy, vol. 44, no. 1, 2006, pp. 1-25.

Herman, Judith. Trauma and Recovery: The Aftermath of Violence-From Domestic Abuse to Political Terror. Basic Books, 1997.

Hettema, John M., et al. "A Review and Meta-Analysis of the Genetic Epidemiology of Anxiety Disorders." American Journal of Psychiatry, vol. 158, 2001, pp. 1568-78.

Hornby, Helen, ed. Lights of Guidance: A Bahá'i Reference File. India Bahá'í Publishing Trust, 1983. 
Hosking, Geoffrey. "The Decline of Trust in Government." Trust in Contemporary Society, edited by Masamichi Sasaki. Brill, 2019, pp. 77-103.

Hwang, T., et al. "Loneliness and Social Isolation during COVID-19 Pandemic." International Psychogeriatrics, vol. 32, no. 10, 2020, pp. 1217-20. doi:10. 1017/S1041610220000988.

Isaak, C. A., et al. "Conceptualizations of Help-Seeking for Mental Health Concerns in First Nations Communities in Canada: A Comparison of Fit with the Andersen Behavioral Model." Transcultural Psychiatry, vol. 57, no. 2, 2020, pp. 346-62. doi:10.1177/1363461520906978.

Jahanshahi, Asghar A., et al. "The Distress of Iranian Adults during the Covid-19 Pandemic - More Distressed than the Chinese and with Different Predictors." Brain, Behavior, and Immunity, vol. 87, 2020, pp. 124-25.

Jones, Antwan, and Diana S. Grigsby-Toussaint. "Housing Stability and the Residential Context of the COVID-19 Pandemic." Cities and Health, 2020, pp. 1-3. doi:10.1080/23748834.2020.1785164.

Kaati, Gunnar, et al. "Transgenerational Response to Nutrition, Early Life Circumstances and Longevity." European Journal of Human Genetics, vol. 15, 2007, pp. 784-90. doi:10.1038/sj.ejhg.5201832.

Kakuma, Ritsuko, et al. "Human Resources for Mental Health Care: Current Situation and Strategies for Action." The Lancet, vol. 378, no. 9803, 2011, pp. 1654-63.

Kessler, Ronald C., et al. "Childhood Adversities and Adult Psychopathology in the WHO World Mental Health Surveys." British Journal of Psychiatry, vol. 197, 2010, pp. 378-85. doi:10.1192/bjp.bp.110.080499.

Kingsbury, M., et al. "The Protective Effect of Neighbourhood Social Cohesion on Adolescent Mental Health Following Stressful Life Events." Psychological Medicine, vol. 50, no. 8, 2020, pp. 1292-9. doi:10.1017/ S0033291719001235.

Kohrt, Brandon A., et al. "The Role of Communities in Mental Health Care in Lowand Middle-Income Countries: A Meta-Review of Components and Competencies." International Journal of Environmental Research and Public Health, vol. 15, no. 6, 2018, pp. 1-31. doi:10.3390/ijerph15061279.

Kola, Lola. "Global Mental Health and COVID-19." The Lancet Psychiatry, vol. 7, no. 8, 2020, pp. 655-57. doi:10.1016/S2215-0366(20)30235-2.

Kong, X., et al. "Altered Autonomic Functions and Gut Microbiome in Individuals with Autism Spectrum Disorder (ASD): Implications for Assisting ASD Screening and Diagnosis." Journal of Autism and Developmental Disorders, vol. 51, 2020, pp. 144-57. doi:10.1007/s10803-020-04524-1.

Laborde, David, et al. "COVID-19 Risks to Global Food Security." Science, vol. 369 , no. 6503,2020 , pp. 500-2. doi:10.1126/science.abc4765. 
Liang, Ronald. The Politics of the Family and Other Essays. Tavistock Publications, Ltd., 1971.

Lynch, John W., and George A. Kaplan. "Understanding How Inequality in the Distribution of Income Affects Health." Journal of Health Psychology, vol. 2, 1997, pp. 297-314. doi: 10.1177/135910539700200303.

Magen, Jed, and Deborah Banazak. "The Cost of Residency Training in Psychiatry." Academic Psychiatry, vol. 24, no. 4, 2000, pp. 195-201.

Marmot, Michael, and Richard Wilkinson. Social Determinants of Health. Oxford Scholarship Online, 2009. doi:10.1093/acprof:oso/9870198565895.001.0001.

Marmot, Michael, et al. "Closing the Gap in a Generation: Health Equity through Action on the Social Determinants of Health." The Lancet, vol. 372, 2008, pp. 1661-9.

Mascaro, Nathan, et al. "The Development, Construct Validity, and Clinical Utility of the Spiritual Meaning Scale." Personality and Individual Differences, vol. 37, 2004, pp. 845-60. doi:10.1016/j.paid.2003.12.011.

Mathers, John C., et al. " 1 - Induction of Epigenetic Alterations by Dietary and Other Environmental Factors." Advances in Genetics, vol. 71, 2010, pp. 3-39. doi:10.1016/B978-0-12-380864-6.00001-8.

McEwen, B. S. "Central Effects of Stress Hormones in Health and Disease: Understanding the Protective and Damaging Effects of Stress and Stress Mediators." European Journal of Pharmacology, vol. 583, 2008, pp. 174-85.

Michael, Tanja, et al. "Epidemiology of Anxiety Disorders." Psychiatry, vol. 6, no. 4, 2007, pp. 136-42.

Neimeyer, R. A., et al. Grief and Bereavement in Contemporary Society: Bridging Research and Practice. Routledge, 2011.

Nicola, Maria, et al. "The Socio-Economic Implications of the Coronavirus Pandemic (COVID-19): A Review." International Journal of Surgery, vol. 78, 2020, pp. 185-93. doi:10.1016/j.ijsu.2020.04.018.

Olfson, Mark, et al. "Trends in Office-Based Mental Health Care Provided by Psychiatrists and Primary Care Physicians." The Journal of Clinical Psychiatry, vol. 75, no. 3, 2014, pp. 247-53. doi:10.4088/JCP.13m08834.

Pearce, Michelle J., and Harold Koenig. "Spiritual Struggles and Religious Cognitive Behavioral Therapy: A Randomized Clinical Trial in Those with Depression and Chronic Medical Illness." Journal of Psychology and Theology, vol. 44, no. 1, 2016, pp. 3-15. doi:10.1177/009164711604400101.

Penn, Michael. "Human Nature and Mental Health: A Bahá'i-Inspired Perspective." The Journal of Bahá'i Studies, vol. 25, no. 1/2, 2015, pp. 25-50.

Pennebaker, James W., and J. A. Skelton. "Psychological Parameters of Physical Symptoms." Personality and Social Psychology Bulletin, vol. 4, no. 4, 1978, pp. 524-30. doi:10.1177/014616727800400405. 
Pierce, Matthias, et al. "Mental Health before and during the COVID-19 Pandemic: A Longitudinal Probability Sample Survey of the UK Population." The Lancet Psychiatry, vol. 7, no. 10, 2020, pp. 883-92. doi:10.1016/S22150366(20)30308-4.

Ren, Xin, et al. "Mental Health during the Covid-19 Outbreak in China: A Meta-Analysis." Psychiatric Quarterly, vol. 91, 2020, pp. 1033-1045. doi:10.1007/s11126-020-09796-5.

Reynaud, Emmanuelle, et al. "Acute Stress Disorder Modifies Cerebral Activity of Amygdala and Prefrontal Cortex." Cognitive Neuroscience, vol. 6, no. 1, 2015, pp. 39-43.

Rhodes, Karin V., et al. "Primary Care Access for New Patients on the Eve of Health Care Reform.” JAMA Internal Medicine, vol. 174, no. 6, 2014, pp. 861-9. doi:10.1001/jamainternmed.2014.20.

Ribeiro, Jessica D., et al. "Depression and Hopelessness as Risk Factors for Suicide Ideation, Attempts and Death: Meta-Analysis of Longitudinal Studies." The British Journal of Psychiatry: The Journal of Mental Science, vol. 212, no. 5, 2018, pp. 279-86.

Rowland, Tobias A., and Steven Marwaha. "Epidemiology and Risk Factors for Bipolar Disorder." Therapeutic Advances in Psychopharmacology, vol. 8, no. 9, 2018, pp. 251-69.

Rüsch, Nicolas, et al. "Mental Illness Stigma: Concepts, Consequences, and Initiatives to Reduce Stigma." European Psychiatry, vol. 20, no. 8, 2005, pp. 529-39, doi:10.1016/j.eurpsy.2005.04.004.

Sani, Gabriele, et al. "Mental Health during and after the COVID-19 Emergency in Italy." Psychiatry and Clinical Neurosciences, vol. 74, no. 6, 2020, p. 372. doi:10.1111/pcn.13004.

Saraceno, Benedetto, and Tarun Dua. "Global Mental Health: The Role of Psychiatry." European Archives of Psychiatry and Clinical Neuroscience, vol. 259, 2009, pp. S109-17.

Sarahian, Nahid, et al. "Effect of Memantine Administration within the Nucleus Accumbens on Changes in Weight and Volume of the Brain and Adrenal Gland during Chronic Stress in Female Mice." Modares Journal of Medical Sciences: Pathobiology, vol. 17, no. 2, 2014, pp. 71-82.

Satici, Begum, et al. "Intolerance of Uncertainty and Mental Wellbeing: Serial Mediation by Rumination and Fear of COVID-19." International Journal of Mental Health and Addiction, 2020. doi:10.1007/s11469-020-00305-0.

Saxena, S. "Challenges and Opportunities in Global Mental Health: A Perspective from WHO.” Epidemiology and Psychiatric Sciences, vol. 25, 2016, pp. 495-8. doi:10.1017/S2045796016000536.

Schotte, Chris K.W., et al. "A Biopsychosocial Model as a Guide for Psychoeducation and Treatment of Depression." Depression and Anxiety, vol. 23, 2006, 
pp. 312-24.

Seligman, Martin E. P. “Learned Helplessness.” Annual Review of Medicine, vol. 23, 1972, pp. 407-12.

Serafini, G., et al. "The Psychological Impact of COVID-19 on the Mental Health in the General Population." QJM: An International Journal of Medicine, vol. 133, no. 8, 2020, pp. 531-7. doi:10.1093/qjmed/hcaa201.

Shoghi Effendi. Arohanui: Letters from Shoghi Effendi to New Zealand. Bahá'í Publishing Trust of Suva, Fiji Islands, 1982.

___. Unfolding Destiny. UK Bahá'í Publishing Trust, 1981.

Shore, David A. The Trust Crisis in Healthcare: Causes, Consequences, and Cures. Oxford University Press, 2007.

Shultz, J. M., F. Baingana, and Y. Neria. "The 2014 Ebola Outbreak and Mental Health: Current Status and Recommended Response.” JAMA, vol. 313, no. 6, 2015, pp. 567-68.

Singla, Daisy R., et al. "Psychological Treatments for the World: Lessons from Lowand Middle-Income Countries." Annual Review of Clinical Psychology, vol. 13, 2017, pp. 149-81. doi:10.1146/annurev-clinpsy-032816-045217.

Statistics Canada. "How Are Canadians Coping with the COVID-19 Situation?" Canadian Perspectives Study Series, 4 Apr. 2020. www150.statcan.gc.ca/ n1/pub/11-627-m/11-627-m2020029-eng.htm.

Sulmasy, Daniel P. "A Biopsychosocial-Spiritual Model for the Care of Patients at the End of Life." The Gerontologist, vol. 42, 2002, pp. 24-33.

Tasca, Cecilia, et al. "Women and Hysteria in the History of Mental Health." Clinical Practice and Epidemiology in Mental Health, vol. 8, 2012, pp. 110-19. doi:10.2174/1745017901208010110.

Trivedi, P. "8 Fold Indigenous Approach for Improving Psycho-immunity: With Special Reference to COVID-19 Pandemic." Dev Sanskriti Interdisciplinary International Journal, vol. 16, 2020, pp. 16-21. doi:10.36018/dsiij. v16i.158.

Universal House of Justice. Letter Written on Behalf of the Universal House of Justice to an Individual Believer, 15 June 1982. Lights of Guidance: $A$ Bahá' $i$ Reference File, $6^{\text {th }}$ ed., compiled by Helen Hornsby. Bahá'í Publishing Trust, 1999.

Message to the Bahá'ís of the World, Ridván 2012. Bahá'i World Centre, 2012. universalhouseofjustice.bahai.org/ridvan-messages/20120421_001.

Van Lancker, Wim, and Zachary Parolin. "COVID-19, School Closures, and Child Poverty: A Social Crisis in the Making." The Lancet: Public Health, vol. 5, no. 5, 2020, pp. 243-4. doi:10.1016/S2468-2667(20)30084-0.

Wallace IV, Edwin R., and John Gach. History of Psychiatry and Medical Psychology. Springer-Verlag, 2008. 
Wissow, Lawrence S., et al. "Universal Mental Health Screening in Pediatric Primary Care: A Systematic Review." Journal of the American Academy of Child \& Adolescent Psychiatry, vol. 52, no. 11, 2013, pp. 1134-47. doi:10.1016/j.jaac.2013.08.013.

Wong, Chee Wai et al. "Digital Screen Time During the COVID-19 Pandemic: Risk for a Further Myopia Boom?." American Journal of Ophthalmology, vol. 223, 2021, pp. 333-37. doi:10.1016/j.ajo.2020.07.034.

World Health Organization and United Nations High Commissioner for Refugees. mhGAP Humanitarian Intervention Guide (mhGAP-HIG): Clinical Management of Mental, Neurological and Substance Use Conditions in Humanitarian Emergencies. WHO, 2015.

Xiong, Jiaqi, et al. "Impact of COVID-19 Pandemic on Mental Health in the General Population: A Systematic Review." Journal of Affective Disorders, vol. 277, 2020, pp. 55-64.

Yip, Paul S. F., et al. "The Impact of Epidemic Outbreak: The Case of Severe Acute Respiratory Syndrome (SARS) and Suicide among Older Adults in Hong Kong." Crisis, vol. 31, no. 2, 2010, pp. 86-92.

Zisook, Sidney, et al. "Psychiatry Residency Training around the World." Academic Psychiatry, vol. 31, no. 4, 2007, pp. 309-25. 